\title{
Espécies arbóreas tóxicas presentes na arborização urbana do município de Santarém, Pará
}

São muitos os benefícios proporcionados pela arborização em vias urbanas, contudo, deve-se conhecer as características das espécies que irão compor a floresta urbana, pois existem plantas que produzem substâncias tóxicas ao ser humano. Este estudo teve como objetivo identificar as espécies com princípios tóxicos arborização urbana de 11 praças e 4 ruas do município de Santarém. Foram inventariados todos os indivíduos arbóreos com altura igual ou superior a 1,5 m. Quanto à origem das espécies, consideraram-se nativas aquelas originárias de formações vegetais ocorrentes no Brasil. As espécies que ocorrem em outros ecossistemas diferentes dos que aparecem em território brasileiro, foram consideradas exóticas e a toxicidade das espécies foi determinada a partir da metodologia de revisão de literatura. Foram identificadas 1656 árvores pertencentes a 48 espécies, onde $21 \%$ exibem algum princípio tóxico, $35 \%$ não são consideradas tóxicas e $44 \%$ não foi possível encontrar na literatura. Foi observado que a maioria das espécies tóxicas são nativas (60\%). Os indivíduos tóxicos mais frequentes foram Mangifera indica L. (Mangueira), com 62,32\%; Azadirachta indica A. Juss (Nim), com 18,37\% e Ficus benjamina L. (Ficus), com 13,85\%. Apesar de 751 indivíduos apresentarem princípios tóxicos não recomenda-se necessariamente a remoção destes, apenas deve-se investir em programas que informem as pessoas do possível perigo que estas espécies representam.

\section{Toxic tree species present in the urban arborization of the city of Santarém, Pará}

\begin{abstract}
There are many benefits provided by afforestation in urban roads, however, one must know the characteristics of the species that will make up the urban forest, because there are plants that produce substances that are toxic to humans. This study aimed to identify the species with toxic principles urban arborization of 11 squares and 4 streets of the municipality of Santarém. All tree individuals with height equal to or greater than $1.5 \mathrm{~m}$ were inventoried. As to the origin of the species, those originating from plant formations occurring in Brazil were considered native. Species that occur in other ecosystems other than those that appear in Brazilian territory were considered exotic and the toxicity of the species was determined from the methodology of literature review. There were 1656 trees belonging to 48 species, where $21 \%$ showed some toxic principle, $35 \%$ were not considered toxic and $44 \%$ could not be found in the literature. It was observed that most of the toxic species are native (60\%). The most frequent toxic individuals were Mangifera indica L. (Mangueira), with 62.32\%; Azadirachta indica A. Juss (Nim), with $18.37 \%$ and Ficus benjamina L. (Ficus), with $13.85 \%$. Although 751 individuals have toxic principles, it is not recommended that they be removed, only programs should be invested to inform people of the potential danger these species pose.
\end{abstract}

Keywords: Mangueira; Forestry; Toxicity.

Topic: Planejamento, Gestão e Políticas Públicas Ambientais

Reviewed anonymously in the process of blind peer
Received: $12 / 04 / 2019$

Approved: 27/05/2019
Sarah Stephanie Rebelo Traian Baumann Universidade Federal do Oeste do Pará, Brasi http://lattes.cnpq.br/7722661512593219 sarah.engflor@gmail.com

Camila Amorim Santa Brígida (iD

Universidade Federal do Oeste do Pará, Brasil http://lattes.cnpq.br/7618034411950250 http://orcid.org/0000-0003-1229-7422 brigida88camila@gmail.com

\section{Jaine Beatriz Sousa da Silva}

Universidade Federal do Oeste do Pará, Brasil http://lattes.cnpq.br/0914434709092709 jainebeatrizsousadasilva11@gmail.com
Pricila da Silva Lima

Universidade Federal do Oeste do Pará, Brasi http://lattes.cnpq.br/0233912900535413 pricila.bibi.7@gmail.com

\section{Livia Karine Lima Rabelo}

Universidade Federal do Oeste do Pará, Brasil http://lattes.cnpq.br/2513116920954057 liviarabello16@gmail.com

\section{Eldeane de Castro Pires}

Universidade Federal do Oeste do Pará, Brasil http://lattes.cnpq.br/4200887834787118 eldeanecastro@gmail.com
Mayra Piloni Maestri (iD)

Universidade Federal Rural da Amazônia, Brasil http://lattes.cnpq.br/2687102042811310 http://orcid.org/0000-0002-8936-952X mayrapmaestri@hotmail.com

Marina Gabriela Cardoso de Aquino (i) Universidade Federal do Oeste do Pará, Brasil http://lattes.cnpq.br/2168843028631934 http://orcid.org/0000-0002-0160-0804 marinaacardosoo@gmail.com
Referencing this:

BAUMANN, S. S. R. T.; BRÍGIDA, C. A. S.; SILVA, J. B. S.; LIMA, P. S.; RABELO, L. K.; PIRES, E. C.; MAESTRI, M. P.; AQUINO, M. G. C.. Espécies arbóreas tóxicas presentes na arborização urbana do município de Santarém, Pará. Revista Ibero Americana de Ciências Ambientais, v.10, n.3, p.342-351, 2019. DOI: http://doi.org/10.6008/CBPC21796858.2019.003.0029 


\section{INTRODUÇÃO}

A Silvicultura Urbana é uma ramificação da silvicultura que engloba o meio urbano, tendo como objetivo o manejo e cultivo de árvores nos espaços físicos das cidades, as chamadas florestas urbanas, com finalidade ecológica, social e econômica (PUENTES, 2005), como por exemplo, a melhoraria da estética das cidades, diminuição da contaminação do ar por meio do sequestro de $\mathrm{CO}_{2}$, moderadoras de temperatura, servem como abrigo e fornecem alimentação para a fauna local e até mesmo para a população local (CORZO, 2010).

Estes atos podem ser realizados por meio de um Plano de Arborização Urbana, feito a partir do inventário da arborização, expondo informações importantes sobre as condições da flora local, necessárias para desenvolver, planejar e executar serviços pertinentes no espaço urbano. Isso é uma alternativa de diminuir os impactos ambientais provocados pelos espaços antropizados, para que ao mesmo tempo a sociedade ganhe benefícios ambientais, culturais, sociais, estéticos e paisagísticos garantindo a sensação de conforto dos cidadãos e promovendo uma harmonia entre ambiente construído e ambiente natural (PAULA, 2015).

Portanto, para que benefícios sejam proporcionados e impactos minimizados é necessária a realização de inventários florestais contínuos da floresta urbana, o que permitirá conhecer a composição, características e comportamento das espécies dentro do espaço físico urbano que se encontra, possibilitando identificar aquelas potenciais, as que devem ser eliminadas e as de maior necessidade de manejo (BOBROWSKI et al., 2011; PORTO et al., 2013). Não raro, os problemas são causados pelo plantio de espécies inapropriadas, gerando danos à saúde humana e infraestrutura das cidades como as redes elétricas, calçadas, muros, poste de iluminação pública, além de gerar acúmulo de resíduos (LIRA, 2014). Com isso, o presente estudo teve como objetivo identificar as espécies com princípios tóxicos na floresta urbana do município de Santarém, oeste do estado do Pará.

\section{REVISÃO TEÓRICA}

Para conhecer a diversidade de espécies vegetais de um local e apontá-las como adequadas para utilização na arborização, é necessário conhecer características como: fenologia, porte do vegetal, frutificação, caducifólia, forma do tronco, características das raízes, velocidade de crescimento e resistência a pragas, doenças e déficit hídrico (RIBEIRO, 2009). A fim de se evitar a ocorrência de espécies com espinhos, acúleos, sapopemas, produtoras de frutos muito grandes e carnosos em espaço físico inadequado, queda periódica de folhas, assim como espécies com princípios tóxicos (CEMIG, 2011).

Para suas atividades vitais, incluindo os mecanismos de defesa, os vegetais produzem substancias químicas como proteínas, lipídios, carboidratos e ácidos nucleicos (SILVA, 2009). No entanto, um número elevado de compostos químicos produzidos pelos vegetais pode servir para outros propósitos, sendo que algumas destas substâncias podem ser tóxicas e irritantes para outros organismos, como: alcaloides beladonados, alcaloides pirrolizidínicos, alcaloides cumarínicos, glicosídeos cianogênicos (HCN), glicosídeos 
cardiotóxicos, oxalato de cálcio, proteínas tóxicas (toxico albuminas), saponinas, resinas (alcoóis, ácidos e fenóis), dentre outros (ANDRADE FILHO et al.,2001).

Esses vegetais estão presentes em jardins, quintais, áreas de produção agrícola, pastagens e também na arborização de ruas, calçadas e praças sem o conhecimento de sua toxidade pelo poder público e comunidade (FURTADO et al., 2012). Sendo muito importante a identificação destas espécies em ambientes que servem de lazer para a população, como as praças e ruas públicas a fim de que problemas a saúde humana sejam evitados (MEDEIROS et al., 2008).

\section{MATERIAIS E MÉTODOS}

\section{Área de estudo}

O estudo foi realizado na cidade de Santarém, município situado na região Oeste do Pará, entre as coordenadas geográficas $2^{\circ} 26^{\prime} 22^{\prime \prime} \mathrm{S}$ e $54^{\circ} 41^{\prime} 55^{\prime \prime} \mathrm{O}$, com uma extensão territorial de $17.898 \mathrm{~km}^{2}$ e, aproximadamente, 302.667 mil habitantes (IBGE, 2019). O clima dominante da região é quente e úmido, característico das florestas tropicais, com temperatura média anual variando de 25 ㅇ a 28 ㄷ C e umidade relativa média do ar de 86\% (SANTARÉM, 2018).

A avaliação da ocorrência de espécies frutíferas concentrou-se em 4 bairros (Aparecida, Centro, Jardim Santarém e Santa Clara) e 11 praças (Barão de Santarém, das Flores, Liberdade, Matriz, Menino Jesus, Mirante, Nossa Senhora das Graças, Parque da Cidade, Pescado, Rodrigues dos Santos e São Sebastião) do município de Santarém, cuja localização estão apresentadas na figura 1.

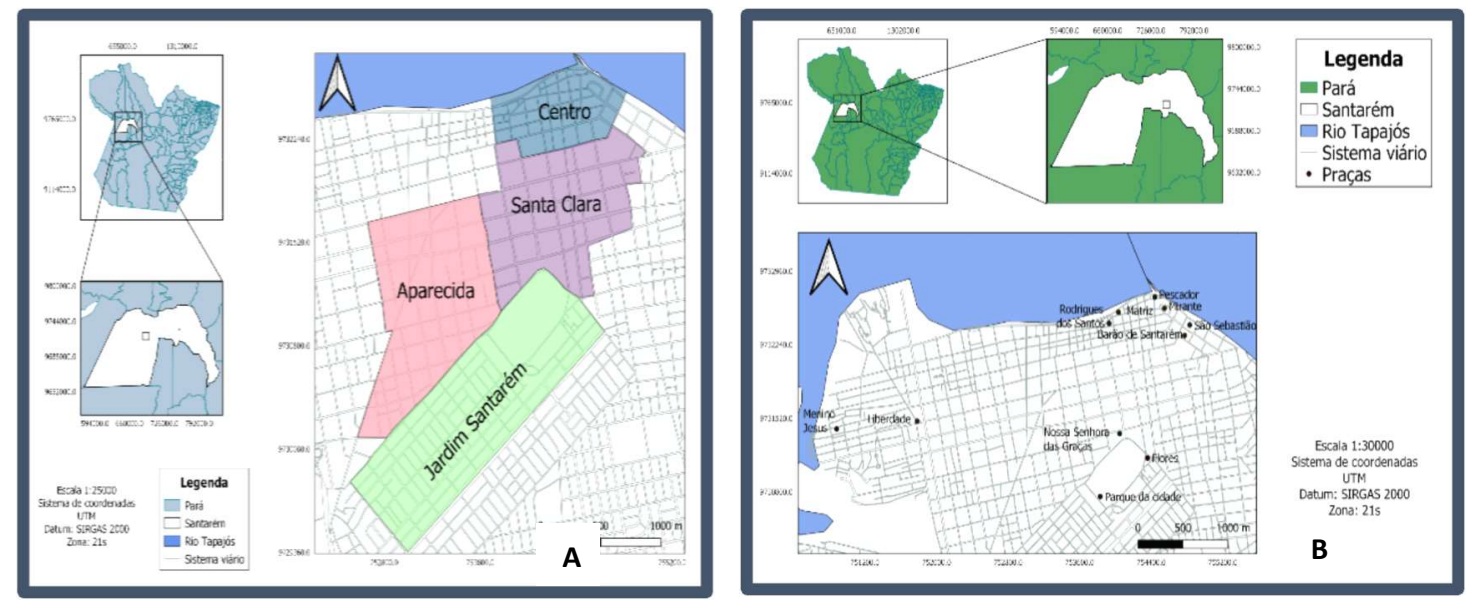

Figura 1: A. Mapa de localização dos bairros B. Praças estudadas.

\section{Coleta e análise de dados}

O censo florístico foi realizado nos meses de novembro a dezembro de 2017 nas ruas e nos meses de novembro a dezembro de 2018 nas praças, onde foram coletados os seguintes dados: nome da espécie, diâmetro a 1,3m do solo (DAP), altura (h) e origem. Foram analisados todos os indivíduos com altura $\geq 1,5 \mathrm{~m}$. Além disso, registros fotográficos de todas as árvores inventariadas foram realizados para auxiliar na identificação botânica das espécies, além da consulta às literaturas especializadas, como Lorenzi et al. (2001) e Lorenzi (2002). Para atualização da grafia dos táxons foi utilizado o sistema Taxonomic Name Resolution 
Service (BOYLE et al., 2013) e o sistema de classificação APG IV foi adotado (BYNG et al., 2016). O cálculo de frequência relativa foi realizado utilizando a seguinte fórmula:

$$
\mathrm{FR}=\frac{n^{\mathrm{o}} \text { de indivíduos }}{n^{\mathrm{o}} \text { de indivíduos total }} \times 100
$$

Quanto à origem das espécies, consideraram-se nativas aquelas originárias de formações vegetais ocorrentes no Brasil. As espécies que ocorrem em outros ecossistemas diferentes dos que aparecem em território brasileiro, foram consideradas exóticas, método adaptado de Paula et al. (2015). A toxidade das espécies foi inferida a partir da metodologia de revisão de bibliografia proposta por Marconi et al. (2010), onde afirmam que o conhecimento da literatura imprescindível para a não duplicação de esforços, a não 'descoberta' de ideias já expressas, a não-inclusão de 'lugares-comuns' no trabalho. Além disso, a comparação dos resultados obtidos permite salientar a contribuição da pesquisa realizada, demonstrar contradições ou reafirmar comportamentos e atitudes. A tabulação e análise dos dados foram realizadas em planilhas eletrônicas.

\section{RESULTADOS}

Foram inventariadas 1656 árvores pertencentes a 48 espécies. Destas, 10 espécies apresentam algum princípio tóxico, 17 não são consideradas tóxicas e 21 não puderam ser identificadas com presença ou ausência de compostos tóxicos devido à falta de estudos relacionados a toxicidade das mesmas, conforme exposto na figura 2.

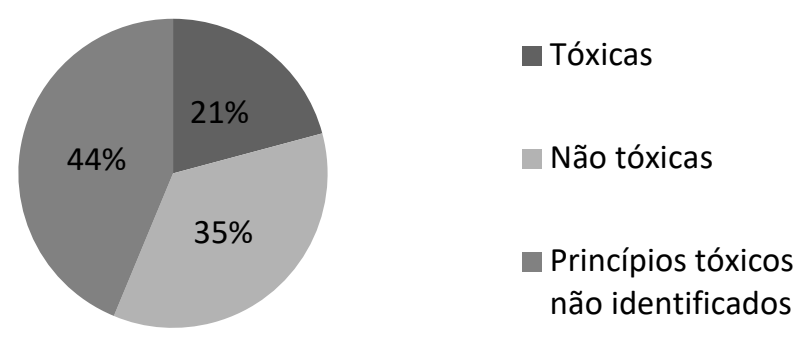

Figura 2: Toxidade de espécies arbóreas da floresta urbana de Santarém/PA.

As espécies cuja toxicidade não pôde ser identificada estão listadas na tabela 1, sendo fundamental o estudo destas para o conhecimento das características que esses vegetais podem vir a ocasionar aos seres humanos, principalmente devido ao fato delas serem utilizadas para arborizar ruas e praças de municípios. As espécies identificadas com princípio tóxico que podem causar reações alérgicas ou danos à saúde de seres humanos e animais correspondem a $21 \%$ das encontradas na floresta urbana de Santarém, totalizando 751 indivíduos, como mostra a tabela 2.

As espécies que apresentaram maior frequência relativa foram Mangifera indica L. (mangueira), com 62,32\%, Azadirachta indica A. Juss (Nim), com 18,37\% e Ficus benjamina L. (ficus), com 13,85\%. Ao analisar a fitogeografia das espécies tóxicas foi observado que elas são em maioria nativas, conforme mostra a figura 3. 
Tabela 1: Espécies sem identificação de compostos tóxicos.

\begin{tabular}{|l|l|}
\hline Nome popular & Nome científico \\
\hline Alfazema & Lavandula officinalis L. \\
\hline Cajuaçu ou cajuí da mata & Anacardium spruceanum Benth. ex Engl. \\
\hline Chuva-de-ouro & Senna ferruginea Schrad. ex DC. \\
\hline Copaibarana & Copaifera sp. L. \\
\hline Cuiarana & Buchenavia grandis Ducke \\
\hline Cuieira & Crescentia amazônica Ducke \\
\hline Ipê amarelo & Handroanthus serratifolius (Vahl) S.O. Grose \\
\hline Ipê Branco & Tabebuia roseo-alba (Ridl.) Sandwith \\
\hline Ipê roxo & Handroanthus impetiginosus (Mart. ex DC.) Mattos \\
\hline Lanterneira ou Lofântera da Amazônia & Lophanthera lactescens Ducke \\
\hline Leucena ou Esporinha & Leucaena latisiliqua (L.) Gillis \& Stearn \\
\hline Louro branco & Ocotea guianensis Aubl. \\
\hline Matafome espinhenta & Acacia obliquifolia M. Martens \& Galeotti \\
\hline Palheteira & Clitoria fairchildiana R.A. Howard \\
\hline Palmeira de salão & Dypsis lutescens (H. Wendl.) Beentje \& J. Dransf. \\
\hline Palmeira imperial & Roystonea oleracea (Jacq.) O.F. Cook \\
\hline Pau Brasil & Paubrasilia echinata (Lam.) Gagnon, H.C. Lima \& G.P. Lewis \\
\hline Sapupira de Varzea & Diplotropis martiusii Benth. \\
\hline Saputilha & Manilkara zapota (L.) P. Royen \\
\hline Sucupira & Andira parviflora Ducke \\
\hline Tento vermelho ou Tento Carolina & Ormosia arborea (Vell.) Harms \\
\hline & \\
\hline
\end{tabular}

Tabela 2: Espécies arbóreas tóxicas da floresta urbana de Santarém/PA.

\begin{tabular}{|l|l|l|l|l|l|l|}
\hline \begin{tabular}{|} 
Nome \\
Popular
\end{tabular} & \multicolumn{1}{|c|}{ Nome Científico } & Origem & \multicolumn{1}{|c|}{ Parte tóxica } & \multicolumn{1}{|c|}{ Referência } & $\begin{array}{c}\text { Frequência } \\
\text { Absoluta }\end{array}$ & $\begin{array}{c}\text { Frequência } \\
\text { Relativa (\%) }\end{array}$ \\
\hline Cajueiro & $\begin{array}{l}\text { Anacardium } \\
\text { occidentale L. }\end{array}$ & Nativa & $\begin{array}{l}\text { Folhas, sementes, } \\
\text { casca e fruto }\end{array}$ & Flores, 2001 & 30 & 3,99 \\
\hline Cumarú & $\begin{array}{l}\text { Dipteryx odorata } \\
\text { (Aubl.) Wild. }\end{array}$ & Nativa & Óleo & Araújo et al., 2004 & 1 & 0,13 \\
\hline Ficus & Ficus benjamina L. & Exótica & Látex & Lopes et al., 2009 & 104 & 13,85 \\
\hline Mangueira & Mangifera indica L. & Exótica & $\begin{array}{l}\text { Exsudato e frutos } \\
\text { verdes }\end{array}$ & $\begin{array}{l}\text { Flores et al., 2001; } \\
\text { Boscolo et al., 2008 }\end{array}$ & 468 & 62,32 \\
\hline Muruci & $\begin{array}{l}\text { Byrsonima sericea } \\
\text { D.C. }\end{array}$ & Nativa & Casca e folhas & Silva, 2016 & 4 & 0,53 \\
\hline Nim & $\begin{array}{l}\text { Azadirachta indica A. } \\
\text { Juss }\end{array}$ & Exótica & $\begin{array}{l}\text { Casca, sementes, } \\
\text { óleo e folhas. }\end{array}$ & Biswas, 2012 & 138 & 18,37 \\
\hline Oiticica & Licania rígida Benth. & Nativa & Folhas & Melo et al., 2015 & 2 & 0,26 \\
\hline Pupunheira & $\begin{array}{l}\text { Bactris gasipaes } \\
\text { Kunth }\end{array}$ & Nativa & Fruto in natura & Small et al., 2005 & 1 & 0,13 \\
\hline Tamarindo & Tamarindus indica L. & Exótica & Casca & Nwodo, 2011 & 1 & 0,13 \\
\hline Taperebá & Spondias mombin L. & Nativa & Folhas & Asuquo et al., 2012 & 2 & 0,26 \\
\hline Total & & & & 751 & 100 \\
\hline
\end{tabular}

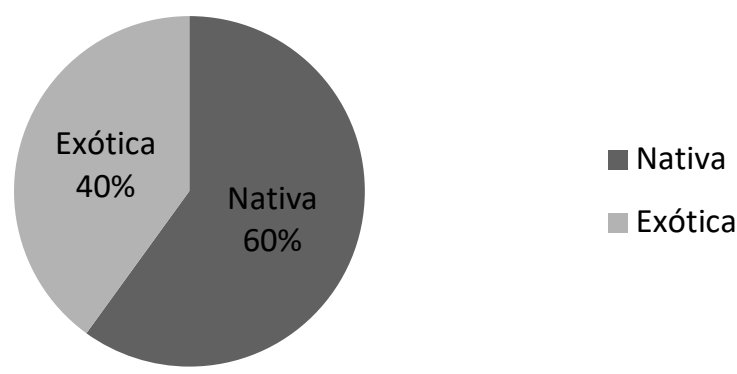

Figura 3: Fitogeografia das espécies tóxicas da floresta urbana de Santarém/PA.

\section{DISCUSSÃO}

Na floresta urbana de Santarém/PA, 21\% das espécies arbóreas possuem a presença de princípios tóxicos. Em Campina Grande/PB, 4,4\% das espécies arbóreas produzidas no Horto Florestal Lauro Pires Xavier são potencialmente tóxicas (CAVALCANTI et al., 2003). Em Santiago/RS, 8,55 \% das espécies podem ser consideradas tóxicas (SOUZA et al., 2019). Pode-se perceber que a cidade apresentou maior porcentagem de 
espécies arbóreas tóxicas em relação às outras cidades brasileiras, o que pode ter sido influenciado pela intensidade amostral utilizada.

Quanto as espécies cuja toxidade não foi identificada, não foram encontrados estudos que relatem informações sobre a presença ou ausência de compostos tóxicos nessas plantas, como por exemplo Handroanthus serratifolius, Senna ferrugínea e Crescentia amazônica. Já as espécies cuja toxicidade foi abordada em literatura consultada estão listadas a seguir:

\section{Cajueiro: Anacardium occidentale L.}

É comum o uso dessa espécie para a fabricação de sucos, produção da castanha de caju e na medicina popular (ANDRADE et al., 2010). No entanto, segundo Flores (2001), A. occidentale possui princípios tóxicos nas folhas, sementes, casca e fruto podendo causar queimaduras na pele e mucosas dependendo da quantidade utilizada. O cajueiro representa 3,99\% das espécies arbóreas inventariadas neste estudo e no trabalho de Silva (2018) na cidade de Paragominas/PA encontrou-se um valor próximo da realidade de Santarém (5,13\%).

\section{Cumaru: Dipteryx odorata (Aubl.) Wild.}

Segundo Pastore Junior et al. (1999), essa planta é bastante usada na medicina popular, na indústria de perfumes (funcionando como fixador) e também como aromatizador de alimentos, bebidas e cigarros. Contudo, a cumarina, presente no óleo essencial da espécie, é uma toxina que pode causar irritação na pele, erupções e toxicidade ao fígado quando usada frequentemente (ARAÚJO et al., 2004). O cumaru representa 0,13\% das espécies arbóreas inventariadas neste estudo. No trabalho de Ferreira et al. (2017), na cidade de Acrelândia/AC, a espécie representa 0,53 \% do total de indivíduos amostrados e no estudo de Araújo (2008) em Sinop/MT o valor aumenta para $0,78 \%$.

\section{Ficus: Ficus benjamina L.}

No trabalho de Lopes et al. (2009), afirmaram que a espécie é tradicionalmente usada no tratamento de distúrbios respiratórios e como cicatrizante de doenças de pele, porém foi constatado que há alérgenos presentes no látex, que após evaporação ligam-se a partículas presentes nas folhas, podendo causar reações alérgicas como rinoconjuntivite, asma, angioedema, prurido e choque anafilático em pessoas que possuem sensibilidade aos compostos. O F. benjamina apresentou uma frequência de $13,85 \%$ no presente trabalho e foi identificado valores semelhantes (12,45\%) no trabalho de Silva (2018), em Vitória do Xingu/PA. Contudo, no estudo de Parry (2012) na cidade de Altamira - PA o valor encontrado foi quase o dobro (24,73\%).

\section{Mangueira: Mangifera indica $\mathrm{L}$.}

De acordo com Shah (2010) é comum o consumo dos frutos da espécie e diversas partes da planta é utilizada para fins medicinais. Todavia, segundo Flores (2001), o exsudato da espécie causa queimaduras na pele e mucosas e o fruto verde pode causar diarreia. As mangueiras apresentaram a maior riqueza de 
indivíduos arbóreos amostrados (62,32 \%) neste estudo. Todavia, os trabalhos de Parry et al. (2012) e Silva (2018) mostraram valores bem inferiores, sendo, respectivamente, 8,76\% em Altamira e 10,26\% no município de Paragomina/PA.

\section{Muruci: Byrsonima sericea D.C.}

Da casca do caule dessa espécie é realizado uma decocção para tratar febres, diarreia, sífilis e doenças renais (AGRA et al., 2007). Porém, no trabalho de Silva (2016), foram registrados efeitos citotóxicos no extrato da casca e das folhas. No presente estudo, a $B$. sericea representa $0,53 \%$ das espécies arbóreas inventariadas, entretanto, o trabalho de Moro et al. (2011), em Fortaleza/CE apresentou a frequência relativa da espécie sendo de $1,57 \%$.

\section{Nim: Azadirachta indica A. Juss}

É utilizada como planta medicinal no oriente (para o tratamento de infecções e inflamações), como repelente natural e como planta ornamental nas vias públicas de cidades (BOTTI et al., 2015). Estudos de Biswas (2012) afirma que foram encontrados aflatoxina e outros compostos tóxicos na casca, sementes, óleo e folhas da espécie, que causa náuseas, vômitos, diarreia, acidose e encefalopatia em humanos. O nim representa 18,37 \% das espécies arbóreas amostradas no presente estudo, contudo, no trabalho de Alencar (2014) em São João do Rio do Peixe/PB o valor encontrado foi de 52,59\%.

\section{Oiticica: Licania rígida Benth.}

Segundo Melo et al. (2015), usa-se as folhas dessa planta para tratar doenças nos rins, perda de peso e na alimentação animal. Mas, estudos realizados em camundongos por esses mesmo autores indicaram que as folhas dessa planta possuem princípios tóxicos e, dependendo da concentração, pode causar a morte desses animais. No município de Santarém a frequência dessa espécie é de 0,26\% sendo esse valor próximo ao encontrado no trabalho de Calixto Junior et al. (2019), em Lavras da Mangabeira/CE que foi de 0,17\%.

\section{Pupunheira: Bactris gasipaes Kunth}

A pupunheira é usada para produção de óleo vegetal, ração animal, comercialização do palmito, farinha para panificação e para o consumo humano de seus frutos (CLEMENT et al., 1987). Todavia, o fruto dessa espécie contém princípios tóxicos e se recomenda consumi-los somente após o cozimento, pois, o calor é necessário para desativar dois fatores tóxicos: o inibidor de tripsina e o ácido oxálico. Os inibidores de tripsina são proteínas que inibem a capacidade de enzimas digestivas para quebrar proteína e os oxalatos facilitam a formação de pedra nos rins, além disso, podem interferir com o metabolismo do cálcio no corpo, especialmente em dietas pobres em cálcio (SMALL et al., 2005). A B. gasipaes representa 0,13\% das espécies arbóreas inventariadas neste estudo, valor próximo ao trabalho de Parry et al. (2012), sendo de 0,09\%. 


\section{Tamarindo: Tamarindus indica $\mathrm{L}$.}

De acordo com Popenoe (1920), praticamente todas as partes das plantas são utilizadas na alimentação ou na medicina popular. Todavia, foram encontrado princípios tóxicos no extrato da casca do caule da planta e, dependendo da dose e do tempo de consumo, o T. indica pode ser bastante perigoso à saúde (NWODO, 2011). A frequência relativa dessa espécie foi de 0,13 \%. Entretanto, na cidade de Altamira o valor subiu para 0,19\% (PARRY et al., 2012)

\section{Taperebá: Spondias mombin L.}

É utilizado algumas partes da planta, principalmente, seus frutos para consumo in natura, processamento de polpa, forragem e suas folhas na medicina popular (LIMA, 2017). Estudos demonstram que a presença de alcaloides e taninos no extrato de Spondias mombin L. provoca a interrupção da secreção do hormônio antidiurético no hipotálamo e desregulação do funcionamento dos rins e do fígado, provocando desidratação e alteração do apetite, quando o organismo está exposto ao extrato por um período prolongado, mais de 4 semanas (ASUQUO et al., 2012). Os taperebazeiros representaram 0,26\% das espécies arbóreas inventariadas neste estudo, em Altamira a frequência relativa desta espécie foi de 0,12\% (PARRY et al., 2012).

Quanto a fitogeografia, $60 \%$ das espécies tóxicas são nativas, resultado semelhante à Cavalcanti et al. (2003) que encontraram $66,5 \%$ de espécies tóxicas nativas. É possível afirmar que a origem da espécie não exerce influência quanto a características tóxicas nas partes da planta, haja vista que espécies não originárias da região não necessariamente representam riscos potenciais a saúde humana ou integridade da fauna.

\section{CONCLUSÕES}

Foi quantificado que $21 \%$ das espécies da área estudada apresentaram princípios tóxicos. Contudo, elas não precisam ser removidas do ambiente, sendo necessário nestes casos investir em programas de sensibilização da população sobre o perigo potencial que estas espécies representam. Além de sua identificação, com placas, dentro da floresta urbana.

\section{REFERÊNCIAS}

AGRA, M. F.; FREITAS, P. F.; BARBOSA FILHO, J. M.. Synopsis of the plants known as medicinal and poisonous in Northeast of Brazil. Revista Brasileira de Farmacognosia, v.17, n.1, p.114-140, 2007.

ALENCAR, L.. Inventário quali-quantitativo da arborização urbana em São João do Rio do Peixe/PB. Agropecuária científica no semiárido, v.10, n.2, p.117-124, 2014

ANDRADE FILHO, A.; CAMPOLINA, D.; DIAS, M. B.. Toxicologia na prática clínica. Belo Horizonte: Folium, 2001.

ANDRADE, M. A.; THOMAZ, L. D.; SILVA, P. A. D.. Plantas medicinais e seus usos na comunidade da Barra do Jucu, Vila Velha, ES. Revista Brasileira de Plantas Medicinais, 2010.
ARAÚJO, R. A.. Florística e estrutura da comunidade arbórea em fragmento florestal urbano no município de Sinop, Mato Grosso. Cuiabá, 2008.

ARAÚJO, V. F.; ECHEVERRIA, R. M.. Sistema de extração de sementes de Cumaru. Organização Internacional de Madeiras Tropicais. Brasília: Universidade de Brasília, 2004.

ASUQUO, O. R.. Evaluation of toxicological effects of Spondias Mombin in adult male Wistar rats. Evaluation, v.2, n.7, 2012.

BISWAS, K.. Biological activities and medicinal properties of neem (Azadirachta indica). Current science-bangalore, v.82, n.11, p.1336-1345, 2002. 
BOBROWSKI, R.; BIONDI, D.. Espécies não tradicionais e espécies indesejáveis na composição da arborização de ruas. Enciclopédia Biosfera, v.9, n.17, p.1293-1304, 2013.

BOTTI, J. M. C.; HOLTZ, A. M.; DE PAULO, H. N.; FRANZIN, M. L.; PRATISSOLI, D.; PIRES, A. A.. Controle alternativo do Brevicoryne brassicae (Hemiptera: Aphididae) com extratos de diferentes espécies de plantas. Revista Brasileira de Ciências Agrárias, Recife, v.10, n.2, p.178-184, 2015.

BOYLE, B.; HOPKINS, N.; LU, Z.; GARAY, J. A. R.; MOZZHERIN, D.; REES, T.; MATASCI, N.; NARRO, M. L.; PIEL, W. H.; MCKAY, S. J.; SONYA, L.; CHRIS, F. P. R. K.; BRIAN, J. E.. The taxonomic name resolution service: an online tool for automated standardization of plant names. BMC bioinformatics, v.14, n.1, p.16, 2013

BYNG, J. W.; CHASE, M. W.; CHRISTENHUSZ, M. J. M.; FAY, M. F.; JUDD, W. S.; MABBERLEY, D. J.; SENNIKOV, A. N.; SOLTIS, D. E.; SOLTIS, P. S.; STEVENS, P. F.; BRIGGS, B.; BROCKINGTON, S.; CHAUTEMS, A.; CLARK, J. C.; CONRAN, J.; HASTON, E.; MOLLER, M.; MOORE, M. J.; OLMSTEAD, R. G.; et al. An update of the Angiosperm Phylogeny Group classification for the orders and families of flowering plants: APG IV. Botanical Journal of the Linnean Society, v.181, n.1, p.1-20, 2016

CALIXTO JUNIOR, J. T. C.; SANTANA, G. M.; LIRA FILHO, J. A.. Análise quantitativa da arborização urbana de Lavras da Mangabeira, $\mathrm{CE}$, nordeste do Brasil. Revista da sociedade brasileira de arborização urbana, Piracicaba, v.4, n.3, p.99109, 2009.

CAVALCANTI, M. L. F.; DANTAS, I. C.; LIRA, R. S.; OLIVEIRA, J. M. C.; ALBUQUERQUE, H. N.; ALBUQUERQUE, I. C. S.. Identificação dos vegetais tóxicos da cidade de Campina Grande/PB. Revista de Biologia e Ciência da Terra, v.3, n.1, 2003.

CEMIG. Companhia Energética de Minas Gerais. Manual para Elaboração do Plano Municipal de Arborização Urbana. São Paulo: Embrapa, 2011.

CLEMENT, C. R.; URPÍ, J. M.. Pejibaye (Bactris gasipaes, Arecaceae): multi-use potential for the lowland humid tropics. Economic Botany, v.41, n.2, p.302-311, 1987.

CORZO, G. T.. Manejo del arbolado urbano en Bogotá. Revista Territorios, n.16-17, 2010.

FERREIRA, E. J. L.; OLIVEIRA, I.; WOLTER, L. T.; PINHEIRO, R. M.; LIMA, P. R. F.. Diagnóstico quali-quantitativo da arborização urbana na cidade de Acrelândia, Acre. In: CONGRESSO BRASILEIRO DE GESTÃO AMBIENTAL CAMPO GRANDE/MS, 8. Anais. Campo Grande: UFMS, 2017.

FLORES, J. S.. Plantas de la flora yucatanense que provocan alguna toxicidad en el humano. Revista Biomédica, v.12, n.2, p.86-96, 2001.

FURTADO, F. M. V.; CARNEIRO, M. S. S.; ARAÚJO, A. A.; GADELHA, C. R.. Intoxicações causadas pela ingestão de espécies vegetais em ruminantes. Ciência Animal, v.22, n.3, p.47-56, 2012.

LIMA, R.. Popular healing practices and medical plants use for riparian mothers in early childhood care Práticas populares de cura e o uso de plantas medicinais por mães ribeirinhas no cuidado infantil. Revista de Pesquisa: Cuidado é Fundamental Online, v.9, n.4, p.1154-1163, 2017.

LIRA, E. S.. Diagnóstico da arborização urbana na área central de Corumbá/MS. In: ENEPEX: ENCONTRO DE ENSINO PESQUISA E EXTENSÃO. Anais. Corumbá: UEMS/UFGD, 2014.

LOPES, R. K.; RITTER, M. R.; RATES, S. M. K.. Revisão das atividades biológicas e toxicidade das plantas ornamentais mais utilizadas no Rio Grande do Sul, Brasil. Revista Brasileira de Biociências, v.7, n.3, 2009.

LORENZI, H.. Árvores Brasileiras: Manual de Identificação e Cultivo de Plantas Arbóreas do Brasil. 4 ed. São Paulo: Instituto Plantarum, 2002.

LORENZI, H.; SOUZA, H. M.. Plantas ornamentais no Brasil: arbustivas, herbáceas e trepadeiras. 3 ed. São Paulo: Instituto Plantarum, 2001.

MARCONI, M. A.; LAKATOS, E. M.. Fundamentos de metodologia científica. 7 ed. São Paulo: Atlas, 2010.

MEDEIROS, L. F. S.; PEREIRA, M.. Espécies com princípios tóxicos, empregados na arborização urbana do bairro Nossa Senhora das Graças - Miguelópolis, SP. Revista Nucleus, São Paulo, v.5, n.2, 2008.

MELO, N. J. A.; SILVA FILHO, E. F.; COSTA, E. L.. Avaliação dos efeitos tóxico e mutagênico do extrato aquoso. Dissertação (Mestrados em produção Animal) - Universidade Federal Rural do Semi-Árido, Mossoró, 2015.

MORO, M. F.; CASTRO, A. S. F.; ARAÚJO, F. S.. Composição florística e estrutura de um fragmento de vegetação savânica sobre os tabuleiros pré-litorâneos na zona urbana de Fortaleza, Ceará. Rodriguésia-Instituto de Pesquisas Jardim Botânico do Rio de Janeiro, Rio de Janeiro, v.62, n.2, 2011.

NWODO, U.. Acute toxicity and hepatotoxicokinetic studies of Tamarindus indica extract. Molecules, v.16, n.9, p.74157427, 2011.

PARRY, M. M.. Composição florística da arborização da cidade de Altamira, Pará. Revista da sociedade brasileira de arborização urbana, Piracicaba, v.7, n.1, p.143-158, 2019.

PASTORE JUNIOR, F.; BORGES, V. L.. Produtos Florestais Não-Madeireiros: Processamento, Coleta e Comercialização. Brasília, 1998.

PAULA, L.; DUARTE, M. S. S.; TOSTES, R. B.; OLIVEIRA JUNIOR, P. R.; RUBACK, S. S.. Arborização urbana do bairro Centro do município de Cataguases, MG. Revista Agrogeoambiental, Pouso Alegre, v.7, n.2, p.101-112, 2015.

POPENOE, W.. Manual of tropical and subtropical fruits: Excluding the banana, coconut, pineapple, citrus fruits, olive, and fig. Macmillan, 1920.

PORTO, L. P. M.; BRASIL, H. M. S.. Manual de orientação técnica da arborização urbana de Belém: Guia para planejamento, implantação e manutenção da arborização em logradouros públicos. Belém: Manual, 2013. 
SANTARÉM. Portal da Prefeitura de Santarém. Santarém, 2019.

PUENTES, D. A.. Florestas Urbanas e Biodiversidades. In: CONGRESSO BRASILEIRO DE ARBORIZAÇÃO URBANA, 9. Anais. Belo Horizonte: UFMG, 2005.

RIBEIRO, F. A. B. S.. Arborização urbana em Uberlândia: percepção da população. Revista da Católica, Uberlândia, v.1, n.1, p.224-237, 2009.

SHAH, K. A.. Mangifera indica (mango). Pharmacognosy reviews, v.4, n.7, p.42, 2010.

SILVA, L. A.. Diagnóstico da arborização urbana da cidade de Vitória do Xingu, Pará, Brasil. Revista da Sociedade

Brasileira de Arborização Urbana, Piracicaba, v.13, n.1, p.5772, 2018.
SILVA, T.. Cytotoxic potential of selected medicinal plants in northeast Brazil. BMC complementary and alternative medicine, v.16, n.1, p.199, 2016.

SILVA, I. R.. Diagnóstico visual e fitossociologia na arborização de praças em Paragominas, Pará. Revista da Sociedade Brasileira de Arborização Urbana, Piracicaba, v.13, n.1, p.1-13, 2018.

SILVA, L. C.. Plantas ornamentais tóxicas presentes no shopping Riverside Walk em Teresina/PI. Revista Brasileira de Arborização Urbana, Piracicaba, v.4, n.3, p.69-85, 2009.

SMALL, E.; CATLING, P. M.. BLOSSOMING TREASURES OF BIODIVERSITY: 16. Peach Palm, Bactris gasipaes: a palm with a heart. Biodiversity, v.6, n.2, p.27-33, 2005.

A CBPC - Companhia Brasileira de Produção Científica (CNPJ: 11.221.422/0001-03) detém os direitos materiais desta publicação. Os direitos referem-se à publicação do trabalho em qualquer parte do mundo, incluindo os direitos às renovações, expansões e disseminações da contribuição, bem como outros direitos subsidiários. Todos os trabalhos publicados eletronicamente poderão posteriormente ser publicados em coletâneas impressas sob coordenação da Sustenere Publishing, da Companhia Brasileira de Produção Científica e seus parceiros autorizados. Os (as) autores (as) preservam os direitos autorais, mas não têm permissão para a publicação da contribuição em outro meio, impresso ou digital, em português ou em tradução. 